Yield is about one gallon. Boil these in a covered container for thirty to forty-five minutes, a slow simmer is fine. Allow to cool and settle for a while. Strain the particles out using nylon hosiery or other filter. Do not use paper filters as these clog quickly. Use clean, sanitized containers for transfer and storage. I strain the liquid while very hot into clean milk cartons. This way the container and brew are reasonably pasteurized. Because of the risk of burn, the beginner should wait until the tea is cool. There are tricks to effective straining which are best learned with cool tea. Keep the stream of tea being filtered to one side of the filter or nylon. If you pour too fast, the peat will form a cap on the filter and the brew will spill everywhere. Plastic containers are best for storage. Do not squeeze out the last bit by hand unless you are not worried about bacteria etc. washing off your hands and into the water! If your yield is much below one gallon, you may add slightly more water at the start of cooking. The $\mathrm{pH}$ of this concentrate, under our conditions, falls between 3.4-3.8.

I use 1-1 1/2 cup of this tea per gallon of water. A pH meter is handy for adjusting the ratio. The $\mathrm{pH}$, as I've been using; should fall somewhere between 4.5-5.4. When watering, drench the media so water comes out the drain holes. Because this method adds chemicals, do not allow evaporation to concentrate, (over time), these chemicals in the soil. Drenching both adds and removes compounds. In nature, tannic waters are usually in motion, whether on the slopes of Mt... Kinabalu or in the acid seeps of Florida. Adding air to the water/tea is probably smart; boiling or treatments usually remove oxygen from the water. Shake the cooled water in a partially-filled, clean jug or pump,(large scale), air into the treatment tank. Most CP benefit from aerated media. A weekly application is probably good to start your own experiments.

Freshly repotted plants probably won't benefit from this treatment; the media still has an acidic/tannic charge. Depending on watering habits, the media will eventually lose much of its acidity and this is when additional tannins, in the form of peat tea or possibly commercial tea, may hold promise for improving the health of carnivorous plants.

Currently, I am experimenting with tannic bark/ leaf mold/peat tea. The test concentrate is a $\mathrm{pH}$ of 3.4-3.8 and is being aerated and dripped over seedling Nepenthes. This very acid liquid may help protect the seedling from pathogens and nutrients present may be absorbed by leaves and/or roots. After three weeks, the test plants have not died or shown change. This test will probably run for 6-12 months before results will be noticeable, unless the test group dies!

Proceed with caution if you decide to experiment with tannic teas. Variables such as water quality, brand of peat or sphagnum and growing media will affect the performance of this method. My results are preliminary and based on our growing conditions. Begin with a limited test group before treating many plants. Compare treated and non-treated plants, preferably of the same clone. I would appreciate hearing from anyone having positive or negative results. Tannic teas may well be a useful technique in carnivorous plant culture.

\title{
The experimental growth trial for Royal Red VFT
}

\author{
by
}

Charles Clarke, 2/F,No. 128, Tai Po Tsai, Clear Water Bay Road, Kowloon, Hong Kong

As part of the application process for Plant variety Rights (PVR), it is necessary to conduct a comparative growth trial. This trial is a scientific experiment to show whether or not the variety for which PVR is sought is distinct from all closest known varieties of "common knowledge". At the completion of the trial, the results are analysed, a standard description is prepared and, along with the final part of the application form, the application is submitted to the PVR Office.

In his article about the saga of D. muscipula Royal Red, (CPN Vol. 25(3), p.90), Colin Clayton made the following claim about the comparative growth trial that I 
conducted to determine whether or not Royal Red was distinct from other known varities of VFT:

"The law states that a qualified person must conduct or supervise trials to establish whether the plant being trialed is distinct from an already known type, before being granted P.V.R. It was here that the major mistake was made. The chosen qualified person - Dr. Charles Clarke - was given a red petioled V.F.T. and an all green V.F.T. to compare it with. After the scientific growing trials (growing the all red VFT alongside the green one), the conclusion was that the red V.F.T. was different from the green one-so the PVR was granted".

Here I would like to correct Mr. Clayton, who must either be unfamiliar with the conduct of scientific research, or has chosen to misrepresent the way in which I performed the trial. It is not possible to provide full details of how the trail was performed in the space available here, but these have been published in the Australian Plant Varieties Journal previously.

Briefly; the experiment was conducted at Exotica Plants' nursery in Queensland (this is acceptable under PVR regulations). No other common knowledge ${ }^{1}$ varieties of Dionaea muscipula were known at the time in Australia, so the comparators chosen for the trial were drawn randomly from a pool of VFT which were either all green or had varying amounts of red pigment on the inner surfaces of their traps. These were labelled as "Typical" VFT. A sample of 30 typical plants was drawn at random from a pool of 37 plants. 23 plants of "Royal Red" were also used for the trial. The unequal sample sizes were not relevant to the statistical methods used. 'The plants were all potted in the same compost and pot type, and were grown together in rows. Only water was added (in equal amounts) to the plants during the trial. The trail lasted approximately three months, through the period of most active growth. Seasonal variations in growth habit were not considered, as they were not necessary to prove distinctness from the comparators.

Each major leaf part was observed on every plant to determine if it was green or red in colour. The distribution of colour in the leaf parts was always totally red or green: there were no examples of parts being part green, part red. The leaf parts examined were: petiole upper surface, petiole lower surface, trap inner surface, trap outer surface, trap margins, and the fringe "hairs" at the margins of the trap. The tone of the red pigment was noted. To test whether the samples were distributed independently of each other, a series of $\mathrm{c}^{2}$ homogeneity test were performed, and significant differences detected for all characters except the inner surfaces of the traps and the trap margins. To support these parametric analyses, a non-parametric analysis (Mann-Whitney U-test) was also performed, based on the same data. This also showed a highly significant difference between Royal Red and the comparators.

This information was sufficient to show that Royal Red is distinct from typical VFT: the only common knowledge VFT known in Australia at that time. Whether these methods will be suitable for other comparisons is difficult to determine, and this must be considered in any future comparisons that were made: the trial was not designed to be universally adaptable to any comparison between varieties of VFT. Physical characteristics were not examined in this trial, nor was flower structure/ colour, as they were not relevant.

I feel that this trial was somewhat more complicated than being given one redpetioled VFT and one all-green one, and being asked to grow them together for a while, as Mr. Clayton claimed, and trust that this brief explanation of the methods used in the comparative growth trial goes some way to clarifying this matter. No doubt this article will raise more questions than it answers, but I would advise those who are curious to find out more to investigate PVR legislation in their country before making further claims or accusations in media such as CPN or the CP discussion group.

${ }^{1}$ Please note that "common knowledge" has a strict definition in PVR legislation, which is provided in my article about PVR which appears elsewhere in this issue of CPN. 